\title{
Disabled people and digitalization: Disruptive documents in distributing digital devices
}

\section{David Knights and Yvonne Latham, Lancaster University}

\begin{abstract}
This article examines the selection process in a pilot project aimed at distributing computers to disabled people to allow for digitalization. Particular attention is paid to the complexities generated by an allocation assessment form, designed to help these people improve their social interactions through electronic media. There is a paucity of discussions on forms in the organization studies literature but when studied, an over reliance on semantics such that their enactment in embodied sociomaterial performances is easily glossed over. Our problematic revolves around how forms and their surrounding sociomaterial performances constitute, but are also transformed by, subjects, objects and organizational relations. The contribution of this article is, therefore, to address the embodied enactments and sociomaterial practices that are embedded within these allocation processes. So, for example, assessors in the project deviated from a strict interpretation of the questions on the form and sometimes ignored clients' responses so as to prevent formal allocations of computers from being seen as illegitimate, and potentially disruptive to the organization's objectives of distributing digital devices. This enabled us to focus on the sociomaterial and embodied relations that are enacted within the selection process and how these place limits on, but also possibilities for, those allocating and those seeking to be allocated computers. The case study shows how distributing computers to disabled people is a complex sociomaterial process that is conditioned by the embodied performances and textual devices deployed. At the same time, the process was informed by humanistic and normalizing assumptions about sociability that are inscribed on the assessment form as criteria for allocating the computers but one implication, we found, has a tendency to reinforce the marginalization of disabled people.
\end{abstract}




\section{Keywords}

documents/forms, selection interviews, embodiment, sociomateriality, disabled people

\section{Introduction}

This is a story about Ron, Chloe and Polly. ${ }^{\mathrm{i}}$ They are disabled people from the North West of England, who, at the time of this research used the care services of a large UK non-profit organization. Controversy surrounds depictions of disability (Holmqvist, Maravelias and Skalen, 2012) not least because descriptions are often grounded in normalising ideologies of ableism that discriminate through stigmatizing those identified as disabled (Shildrick, 2009). As a consequence, while recognizing that no language is entirely free of performative effects as discussed later in this article, we employ the terms disabled people and impaired bodies as what may be seen as a least worst usage. This care organization had initiated and funded a pilot project called CommunITy whose purpose was to provide 25 disabled people with reconditioned computers, necessary peripherals and, thereby, access to the Internet. The selection criteria revolved around the potential for disabled people who live on their own in geographically remote areas to benefit from technology (IT), especially in relation to their participating more fully in the social world. Underpinning this was the belief that the way in which to facilitate this participation was to normalise disabled people through technology. The organizing principles of the CommunITy project, therefore, can be said to have emerged from ableist normative assumptions, where disabled people are seen as lacking something that can be 'fixed' so as to make their lives similar to those of the able-bodied (Williams and Mavin, 2012).

The research highlighted how filling in assessment forms is an ongoing embodied sociomaterial process in which the complexities of people/subjects and objects/materialities inherent in these processes are obscured as the administration is managed in practical, contextualized situations. The article focuses on the ongoing embodied, sociomaterial 
performances that are enacted as the assessment form ${ }^{i i}$ is deployed as a framing device during selection interviews.

Our research concerns the comparative neglect of discussions of disabled people in organization studies, although the specific problematic of this article revolves around how forms and their surrounding sociomaterial performances constitute, but are also transformed by, subjects, objects and organizational relations. As we proceed through our analysis, we identify how these assessments are informed by humanistic and normalising assumptions concerning individuals realising their potential to be sociable. In the conclusion, we explore how this can have the unintended effect of reinforcing, rather than diminishing, the marginalization of disabled people. We also address the over-reliance on semantics or texts within the literature on forms, which obscures the embodied sociomaterial performances of their enactment $(\mathrm{Mol}, 2002)^{\mathrm{iii}}$. In part, our research parallels that of Cooren, Kuhn, Cornelissen and Clark (2011) who argue that 'the vast majority of the work on organizational communication and discourse tends to focus on the textual aspects' (p.1151) at the expense of what human agents do (wear, look, behave) and what is done by non-human agents. Seeking to extend beyond these textual or semantic analyses, our research questions are: what embodied sociomaterial performances are involved in the enactment of forms and how can they obscure the embodied experiences of disabled people? On an empirical level, we provide an ethnographic 'observer participant' (Wacquant, 2015) account, which serves to confront the interactional entanglements (Barad, 2007) of embodied subjects (e.g. charity agents, a researcher, carers, disabled people and their relatives), their identities and expectations, and the objects (e.g. forms, computers, beds, wheelchairs), all of which constitute their sociomaterial accomplishments. With that in mind, we develop a theoretical framework through which to analyse the sociomaterial embodied performances that took place as the form was deployed within, and indeed beyond, the selection interviews. Our contribution on a theoretical level 
allows us to address the paucity of discussions on forms in the organization studies literature. This complements but also adds a distinctive dimension by highlighting how the form had certain agency and implications for disabled people but part of the analysis is about how human agents had to work on violating both the letter and spirit of the form in order to deliver on organizational demands to allocate computers.

The article is comprised of five main sections. First we provide a brief examination of the literature on embodiment and materiality in order to develop a theoretical framework for our empirical study. This framework is drawn upon in the second section to explore our problematic, which is the paucity of analysis of forms or documents and/or the tendency to over-focus primarily on semantics at the expense of the embodied sociomaterial performances of their enactment. As our empirical data illustrates, these performances have a tendency to obscure the embodied, practical experiences of disabled people and those engaged in some capacity with their care. Thirdly, we offer an overview and critical engagement with our assumptions and some of the methodological practicalities encountered in the field. Fourthly we turn to our empirical material to discuss the performances that ensued as the assessment form was deployed in selection interviews for allocating computers. This is followed by a discussion section which draws on the theoretical framework and the literature of documents and organization more generally to analyse the empirical material. Finally we offer some concluding remarks to summarise the significance, contributions and implications of the article.

\section{Embodiment and materiality}

A critique of the tendency within certain strands of organization studies to privilege technology or humans, as if either could be seen as discrete entities that determined the other, facilitated space for a view of their sociomaterial entanglements. While clearly recognising that 'there is no social that is not also material, and no material that is not also social' (Orlikowski, 2007 p.1438), the embodied nature of these assemblages was not always given attention. Other 
literatures have, however, stressed the importance of bodies and embodiment (able and disabled) in analyses of social and organizational life (Dale, 2005; Grosz, 1994; Mol, 2002; Pullen, Rhodes and Ten Bos, 2015; Wacquant, 2006). A major strand of this literature is to challenge the dominant liberal and neo-liberal traditions that have prevailed in Western economies through an enlightenment philosophy underpinned by a Cartesian belief in the body as subordinated to the mind (Grosz, 1994). By seeing the mind as an idea of the body (Spinoza, 1955), it becomes impossible to separate them let alone subordinate one to the other. Consequently, it is no longer exceptional to engage with individuals as integrated, embodied subjects, as occurs in everyday life by contrast with how academic representations of the body are often presented. Furthering this debate, in her discussions of embodied subjectivity, Dale (2005) argues that this Cartesian split often leads to assumptions of generalized 'normal' bodies as bounded entities, assumptions which obscure the particularities and processes of bodies. For her, "'Embodiment" is much more active, indicating the negotiation of everyday life in relation to the material world and to the creation of social life' (p.655).

This sociomaterial way of thinking (Barad, 2003, 2007: Braidotti, 2011) sees events as comprising internally related, yet unbounded, elements that 'don't precede, but emerge from or through, their intra-action' (Barad, 2013, p.30) and are thereby always in processes of becoming. In social life, bodies and objects are 'partial' in the sense that they are never separate and self-contained. Shoes, for example, are only realised as such when worn by bodies preparing to walk the streets and, at that point, bodies, shoes and pavements all merge into 'a dynamic network of convertibilities' that momentarily are defined 'through assemblage' with one another (Cooper, 2001, p.25). This reflects an understanding of the entangled intradependence and undecidability of the boundaries between 'things' and 'body-agents' (Barad, 2003) or how we represent the world of objects partly to arrest the instabilities of our bodies and selves (Cooper, 1993, p.280). 
This representation of bodies in objects and their inverse helps us to explore how, in practical and situated circumstances, their attributes and the material world they inhabit involve dynamic, mutual exchanges. Within science and technology studies, there are a number of commentators who discuss exchanges in attributes between impaired bodies and the made world (see Mol and Law 2004; Moser and Law 2003; Moser 2005). Moser (2005, p.671) highlights the inter- and intra-related nature of impaired bodies and materialities in her discussions of an 'order of the normal' and the encounters of a man named Jarle who 'is paralysed from the neck down and needs a ventilator to breathe'. She discusses the materialities (in this case an environmental control system) whereby sucking and blowing into a pipe activates a computer to scan and communicate 'all the alternatives aloud', thus facilitating his living at home. It was then possible for Jarle to select his options and manage his space (including calling for assistance), according to his requirements. These are not social events that can be separated in order to be located and analysed but emerge in practice, and are better seen as 'different moments in the unfolding biography of the artefact' (Bloomfield, Latham and Vurdubakis, 2010, p.429). More importantly, there are complex inter- and intraconnections where impairment is managed through material artefacts against a background of embodied experience through various social and organizational constructions. Thus, embodiment can be seen as that which 'accommodates not simply the body, but the manner in which it is experienced and lived as an embodied subject' (Shildrick, 2009, p.18) within a sociomaterial world. In addition, these exchanges involve 'heterogeneous engineering' (Law, 1987) and entanglements/intra-actions between different bodies and sociomaterialities (Dale and Latham, 2015). Take parking a car as an example. One day reverse parking in a tight spot, in between 2 other cars is relatively easy for the experienced driver - a 'good' parking day. The next day, however, might generate difficulties for the driver - a 'bad' parking day. Neither the subjects or the objects may have changed but different particularities are being enacted to 
constrain the performance within specific, situated and practical situations. This example is a little simpler than the accounts concerning the allocation of computers to disabled people where a multiplicity of objects and subjects as well as their entanglements are involved. Bearing the preceding discussion in mind, we now turn to the focus of our research which is to theorize forms and their enactments to show how they are inseparable from the organizational and embodied world that their entanglement reflects and reproduces.

\section{Documents and Organization/Organizing}

As indicated at the outset, forms or documents are powerful devices that are not only a product, but also important in the constitution and reconstitution, of organizations. We illustrate this initially by drawing on different examples where the document is perceived as an object that ascribes, confines, describes and enacts particular versions of bodies, people and practices.

Various commentators have highlighted the constitutive aspect of texts and textual agency in organization/organizing (Cooren, 2004, 2011; Iedema, 2007; McLean and Hoskin, 1998; Smith, 1978). For example, Lennie (2001) discusses the role of written plans in the constitution of organizational reality and argues that 'a plan, in giving direction, confers shape and substance on the world' (p. 48) and, even when there are deviations, arguably sets the parameters of action. Certain events are then selected out of given situations which lead to what may be seen 'as mappings' (Cooper, 1986, p.301).

These selection processes are examined by Smith (1978) in her discussion of an interview to decide whether or not a woman named ' $\mathrm{K}$ ' had a mental condition. She indicates how in such interviews everyone involved carry with them pre-conceived ideas of what is and what is not a mental condition and whether a particular individual fits the category. As part of any interview, a 'cutting out' procedure takes place in which only certain features and events of the actual process are selected and documented. Moreover, during this process, the 
assumptions or pre-conceived ideas that precede the interview are no longer visible - they are, in effect, written out.

Directly in line with our focus on assessment interviews, the form serves to standardise categorisations as well as to constitute subjects and this is key to our understandings of how 'things' are performed in the reproduction of organizations. For McLean and Hoskin, (1998, p.537), the scene of the form is like the staging of a play. 'At first before the curtain rises, the props are ready, and the script in place, but in suspended animation until the dramatis personae enter to play out the roles that text and context open up. Engaging with the script, moving between foreground and background across different moments and situations, they become readable in their truth, as this personae or that.'

It needs to be recognised that by contrast with some documents (e.g. constitutional or legal rules), forms are only partially written and can be said to act 'on behalf of or in the name of the organization' (Cooren, 2004, p.379). As a result, they await completion in being 'filled in', and it is this process that is our focus.

Implicit in much of this discussion is how human agency/embodiment affects, or contributes to, the constitution of organization that takes place during processes of organizing; in other words, 'the moving between foreground and background across different moments and situations' (McLean and Hoskin, 1998, p.537) and the adding on of bits, 'endowing with organs' (p.537). These studies usefully identify the part that all kinds of documents play in the constitution of organization. However, the explicit focus on the semantics of written texts has a tendency to obscure their conditions of possibility in embodied performances.

This lack of focus on embodied performances has to a certain extent been addressed in other fields. Within sociological research, Bittner's (1967) study of the police on skid row, Garfinkel's (1967) studies of suicide and Reed's (2006) discussions of the warrant cover or prison intake document, for example, focus on the agential experiences and bodily 
performances taking place as documents are enacted within practical and situated circumstances. To illustrate, Reed (2006) examines these with reference to a prison in New Guinea where warders employ 'force to extract answers to the questions on the warrant cover' (p.163), whilst 'inmates do their best to conceal or disguise their own biographies' (p.163).

Closer to our field, Shildrick and Price (1996) discuss the claims procedure for Disability Living Allowance (DLA) and how the self-assessment form is crucial. The questions claimants are asked to answer in order to complete the form (in respect of washing, dressing, using the toilet etc.) imply that impairment is a 'fixed' category, in advance of it being observed. Completing the form produces objectifications that enable bodies to be recorded on the appropriate self-assessment form as 'broken' and fixed in this or that way. However, this is not the case for the impaired body, in so far as conditions (such as whether an individual is able to wash, dress or use the toilet) are forever changing, often on a daily basis. For whether or not the body is impaired, it is 'always at risk of disruption' and of threatening the stability of organization but this is most evident when 'the body resists not just conscious control but predictability' (Price and Shildrick, 2002 p.68). As identified above, the form can be seen as an organizational attempt to render impaired bodies predictable.

These latter studies challenge the concentration on semantics by highlighting the importance of bodies and embodiment in discussions of documents. However, they are less explicit in revealing necessary 'intra-actions' (Barad, 2003) of embodiment and materiality. Intra-action reminds us "that "concepts"... and "things" do not have determinate boundaries, properties or meanings apart from their mutual intra-actions' (Iedema, 2007 p.819-820). We now turn to a discussion of our research methodology before presenting the empirical findings.

\section{Methodology}

The purpose of the CommunITy project was to recruit and select 25 'suitable' recipients who would use the computers for social interactive purposes. Our empirical data is drawn from 
fieldwork undertaken by one of the co-authors (researcher) in the North West of England. The stage of the fieldwork being discussed relate to the selection of 'suitable' users, which covered the period from 2006-2008 although reflections on this data are facilitated by longitudinal involvement which lasted for a period of almost 10 years. Some 18 months prior to the researcher's involvement, 25 disabled people had been identified, interviewed and accepted onto the project. However, during this time, the providers of the 25 reconditioned computers facilitating the project had become bankrupt and although a new provider had been identified, several of the identified users had either pulled out of the project, bought a computer of their own and, in one or two cases, had sadly died. When the researcher entered the organization, therefore, 13 new users were needed. At this time, the project co-ordinator (Jack) was in the process of recruiting the remaining users needed to fulfil the remit of the project. Appointments were made by him for a visit to be made to each potential user's home for a selection interview. The researcher was involved with the 13 interviews ${ }^{\text {iv }}$.

Jack and the researcher began an interview programme using an assessment form designed by Jack. There were a variety of reasons for the selection of the three users discussed in this article and for why we give much more space to our first case study where Ron was the applicant. Firstly, Ron's interview was the first that the researcher was involved with and the case study served as a model of the interviewing process for all three. Secondly, the time spent with these participants was longer and the visits more frequent than with many of the others. As a result, the interactions between the researcher and the various participants resulted in rather richer longitudinal data from before, during and after the interviews than was possible with the other applicants. Finally, the researcher's involvement with these participants exposes “'hot spots' that 'glow' for the researcher, whether encountered during the fieldwork, analysis or later" (Harding, Ford and Lee, 2017 p.1215). These are the cases that best exemplify how the initial requirements were negotiated in order to complete the form 
and allocate the computers. These were negotiated in all of the 13 interviews. Of course, there were both positive and negative outcomes, for some recipients still use the computers saying "they would never be without one now" whereas others have either returned or never use them. The form to assess suitability was used to guide discussion in all of the interviews and was, in most instances, completed in part during the interview situation and then finalised after the interview. The interviews were recorded, with permission, using a digital voice recorder but, in addition, the researcher kept a diary throughout the project in which the details of each visit were noted as soon as possible. All interviewees were assured of confidentiality and anonymity should the data generated from their interviews be used in future academic or practitioner discussions of the project. At all the interviews, the researcher was introduced not only as external to, but also as a participant in, the project; she was seen and began to see herself as a member of the organization ${ }^{\mathrm{v}}$ since she was fully active and immersed in the setting. In relation to this, Wacquant (2006) suggests that we need to foster long-term, intensive, even initiatory, forms of ethnographic involvement to allow the investigator to master, in the first person, the social phenomena being investigated. In terms of data analysis, this was very much guided by the events that occurred in the field in relation to the sociomaterial complexities and the disruptions resulting from the enactment of the assessment form. As these evolved, through her own reflections, the researcher selected a range of these and recorded in the research diary. Accordingly these complexities, each of which differed in individual and embodied sociomaterial circumstances, were analysed in relation to the inscriptions on the assessment form, the aims of the project as inscribed on the initial proposal document, and the actual events that took place in the field.

The nature of this methodology sometimes comes at a cost. Firstly, it is difficult to separate yourself from the lived reality in order to make sense of it. However, this is partially overcome through joint authorship with a colleague who has not conducted the empirical 
research. Secondly, as Coffey (1999) suggests, ethnographic methodologies might produce something of a 'passionate analysis' whereby the researcher's own ethical engagement plays a key role in the representation of data (Dale and Latham, 2015). Thirdly, and to illustrate the previous point more fully, Geertz (1973) discusses how these writings/representations could be classed as 'fiction' since they are 'crafted by their authors' (cited in Atkinson and Hammersley 1994 p.254). Indeed, it has been claimed that our empirical research often 'serves only as excuses for our theoretical works that are essentially fictions' (Rhodes and Brown, 2005 p.483). So, not only do the practical and situated circumstances come to be modified by the researcher's engagement in them, so too does the knowledge produced as a result of this engagement. However, to be overconcerned about these matters is usually a legacy from our positivist past where, even when committed to phenomenological or poststructuralist analysis, we cannot help looking over our shoulder, anxious that we might meet with the wrath of the oppressive scientistic master who denies us space for the body and embodiment (Thanem and Knights, 2019), or the serendipity of random events and elements of disorder.

Accordingly, a reflexive methodology has been adopted whereby rather than falsely denying or discounting the multiplicities of complex interactions and intra-actions between subjects, bodies and representations, we approach 'the process of subject formation in a distributive, dispersed and multiple manner (Braidotti 2011 p.165)' through ontoepistemological thinking (Barad, 2007). This means that we regard not only the research participants, but also the researchers, as engaged in complex embodied sociomaterial relations of interpretation and representation that reflexively form the images, materials and meanings from which we articulate a research account.

\section{Constituting the User: The Form}

The project's co-ordinator (Jack) had developed/designed an assessment form to be used for the interviews of all potential service users. The form consisted of seven sections and had 
inscribed within it a series of questions typical of which are the ones regarding IT requirements (see figure 1 below).

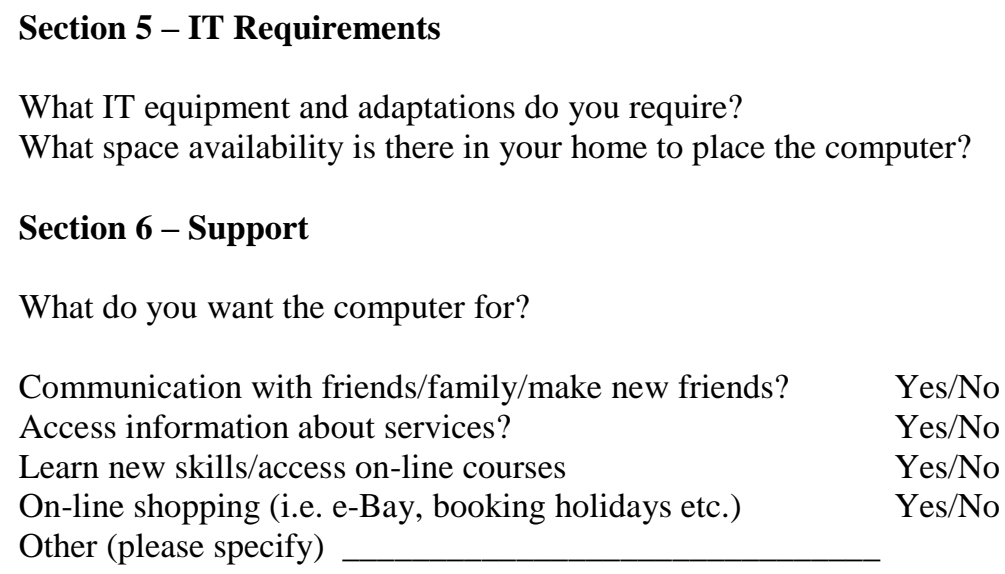

Figure 1 - The Assessment Form ${ }^{\text {vi }}$

The original template for the assessment form was taken from a project named Workability initiated 10 years earlier by the same organization aimed at providing disabled people with reconditioned computers to facilitate access to the workplace. Guided by this and the initial proposal document for the CommunITy project, Jack designed the form in relation to how the organization expected the 25 potential recipients to use the computer 'to maximise their involvement in social, recreational, leisure and educational development'. This is evident in Section 6 of the form, which asks the question 'what do you want the computer for?' There are a list of fixed yes and no response boxes to all the questions, arguably pushing respondents in a certain pre-defined direction of seeing the computer as facilitating more social interaction as a means of reducing their isolation. The final open question of other (please specify) provides for some different responses but because of the closed nature of all the other questions, respondents were left apparently in some difficulty. For example, a number of the participants interviewed would ask for further clarification of an 'open' question and seemed more 
comfortable with those requiring fixed answers. This was partly because they had little or no prior experience of using a computer.

The questions inscribed on the form have been selected (Cooper, 1986) out of a variety of situations and circumstances including, for example, the Workability project, its aim to reduce the social exclusion of disabled people from the workplace, the assumption that technologies can help to achieve this aim, combined with Jack's interpretations of the project, informed by the initial proposal document. A mapping/cutting out procedure has taken place and, in terms of selecting suitable users, the scene has been set (McLean and Hoskin, 1998) enabling certain sociomaterial and embodied accomplishments. We now turn to the three empirical case studies that we have selected as a way of illustrating our arguments, first of which is the full selection interview script of the allocation to Ron after which we briefly consider Chloe and then Polly.

\section{The Selection Interview}

Case Study 1 - Ron

What follows is a discussion of an interview, which took place as Ron was being assessed as a potential CommunITy user whilst lying in bed at home. Ron was in his early fifties and an expoliceman. He had multiple sclerosis and as a result of the deterioration of his body, was categorised as quadriplegic. He was only able to move from his neck upwards. He had a $\operatorname{possum}^{\text {vii }}$ to operate his telephone, his television, his lights and his front door. Ron lived in a supported living scheme and was supported by staff on a 24-hour, daily basis. He did therefore have quite a high degree of social interaction with his support workers. He also had a lot of interaction and care from various family members. He did get out of the house but this was only with help and these times were limited to approximately once a month.

Present at the interview were Ron, his sister/carer, a key/support worker, Jack (the coordinator) and the researcher. Below is a transcription of the interview process in which the 
assessment form was used as a guide to discussion although there was not always a strict adherence to the questions inscribed on the form. The form was completed some days following the interview process.

Jack outlined to Ron that the aim of the project was to allow people more access to the outside world in an attempt to increase their social interactions. Jack introduced the researcher to Ron as someone who was to spend a period of time involved in the project, with a view to writing an evaluation report.

Researcher: As Jack said, I'm working on the evaluation side of the project in the hope that we can see how or whether expectations have been filled further down the line. The first thing is, how or what made you think about having a computer with regard to this project?

Ron: [Points to key worker] Her fault. [Jokingly]

Keyworker: My service manager mentioned it and asked if Ron might be interested, so I mentioned it to Ron and he expressed an interest.

Researcher: How familiar are you with computers? Have you used them before?

Ron: $\quad$ Yes.

Researcher: Are you confident with regard to what you can access etc?

Ron: $\quad$ Yes. Erm, in what respect?

Researcher: In what places, sites etc, chat rooms?

Ron: $\quad$ No, not in that respect. The computers I have used had round about 30 million cars, with names, addresses and details. It had round about 40 million people.

Carer: $\quad$ Not used it for recreation.

Researcher: What are your expectations with regard to your own life? Do you think it will improve?

Ron: $\quad$ Buying and selling shares if I find it easy enough. 


\begin{tabular}{|c|c|}
\hline Researcher: & What about meeting new people on line? \\
\hline Ron: & No, not interested. Just want to research info, buy stuff, sell stuff. \\
\hline Researcher: & What about shopping, as in general shopping? \\
\hline Ron: & No, Maggie [sister/carer] does that. \\
\hline Researcher: & Do you not think you will use the email? \\
\hline Ron: & No, I'd rather phone up. \\
\hline Researcher: & $\begin{array}{l}\text { Would you access sites which have forums where people engage with each } \\
\text { other? }\end{array}$ \\
\hline Carer: & $\begin{array}{l}\text { He can't be civil to anyone. He's not sociable. He's horrible. [this came across } \\
\text { as slightly joking but with a serious undertone] }\end{array}$ \\
\hline Ron: & $\begin{array}{l}\text { No, I won't interact. I'm miserable like my brother. [Ron sounded serious when } \\
\text { he said this] }\end{array}$ \\
\hline $\begin{array}{l}\text { Carer: } \\
\text { Researcher: }\end{array}$ & $\begin{array}{l}\text { Can you play games on it? } \\
\text { Yes. }\end{array}$ \\
\hline \multicolumn{2}{|c|}{$\begin{array}{l}\text { The researcher told them about one of the games } \\
\text { time whilst playing this game she bumped into son } \\
\text { character's life. }\end{array}$} \\
\hline Ron: & $\begin{array}{l}\text { I'm more into logical games. I like logical things. Things you've got to work } \\
\text { out and think about. }\end{array}$ \\
\hline Carer: & That'll keep your mind active as well. It'll be good for him. \\
\hline Ron: & Yes. \\
\hline
\end{tabular}

It will be recalled that the form was being used in order to assess which people were most suitable for the CommunITy project. These would be disabled people who wanted a computer with Internet access in order that they could communicate with others, shop online 
etc, resulting in an increase in their social interactions (i.e. section 6 of the form). Ron's responses in relation to not wanting to use the computer for socialising in this way could have disqualified him from being allocated a computer. However, this discrepancy was ignored when the form was completed since it was felt that Ron complied with the spirit, if not the 'letter', of the project even though he did not strictly meet the criteria inscribed in the form. So, what Ron as a physical and social being found appropriate and what was being offered to him socially were incompatible - his physicality and sociality were arguably entangled in complex ways that were not consistent with the aims of the project.

In the open question, respondents are encouraged to think about other uses for the computer, and Ron's carer pre-empted his response by asking, 'Can you play games on it?' Ron demonstrates an interest only in logical, not social, games but this enabled his carer to assert, 'That'll keep your mind active as well - it'll be good for him', thus providing some appropriate material for completing the form. To this final response of 'other (please specify)' the completed form reads, 'To play games online'. Therefore, although the main reason Ron gave as to why a computer would be useful to him was the ability it would give him to deal with his finances, this was not indicated on the assessment form. The question needs to be asked as to why this was the case? We would suggest that 'to play games online' was a better fit for the notion of increasing social interaction on the basis of which the project was developed/designed. This was selected/cut (Smith, 1978) from the discussion and inscribed onto the form as it was seen as a more suitable response than the one given by Ron i.e. 'buying or selling shares'. The reason for this selection was that it followed the researcher's daughters positive social experience of playing an online game. Thus, in this particular instance, it indicated a possible or more likely way than buying and selling shares to increase Ron's social network and thus reshape in the written document the actual embodied sociomaterial performances that had taken place. ${ }^{\text {viii }}$ 


\section{Interview inconsistencies and frustrations}

The conversation (related to section 5 of the form) turned to what, where, and how Ron could set up a computer in order for it to be useable. Jack asked him about his IT requirements. Ron responded that this is what he thought the meeting was about. At this point there was some confusion as none of those present were IT specialists and had little knowledge of what adaptations etc. were needed or could be bought. Ron's carer mentioned a laptop but the project had been provided with 25 reconditioned computers and a relatively small budget for adaptations but also Ron had indicated that a laptop was not feasible because of his spasms. We see evidence here of what Cooper (1993) might call the mis-representation of bodies in technologies for there was no way he would be able to use a laptop. There were problems of accessibility and space. [Ron lives mainly in a small bedroom in which there is his large hospital type single bed, his large flat screen TV which is mounted on the wall and just enough room at either side of his bed for one person to be able to walk and care for him]. He spoke about the support staff/carers being able to move the computer out of the room [the idea being that this would be next to his bed on a work station with wheels] when they needed to get access to him. Observing Ron's bodily expressions during this interview, the researcher was able to identify the building up of frustrations. For example, he started to roll his eyes, to shake his head and it was visually obvious that the conversation was beginning to annoy him. His frustrations were made explicit when he stated, angrily, "no one is listening to me". In some sense, Ron was voicing a concern of being ignored by professionals, whose organizationally and form driven preoccupations with managing the allocations, were seemingly given precedence over the wellbeing of their clients.

Managing the inconsistencies

Directly after the interview, Jack and the researcher discussed how Ron was not really a suitable candidate in terms of the formal aims of the project since he was neither socially or 
geographically isolated. ${ }^{\text {ix }}$ This they reasoned was a result of the amount of interaction he had with his carers and the support staff whom he sees frequently throughout the day. Another potential reason for refusing an allocation was his apparent unwillingness to see the computer as a tool for improving his social interactions since he was only interested in games of logic or playing the stock market. Despite these reservations, it was eventually agreed that Ron was someone who would benefit from having a computer with Internet access. This, it was felt, could lead to an increase in his independence (i.e. he could shop online, deal with his finances without the assistance of his sister or support workers) as long as he was able to use the computer without too much difficulty. They discussed also how once he got online the likelihood was that he would use email and communicate with others on an informal level. In their thinking the chances were that his social networks might also increase (thus fulfilling the formal aims of the project) so Jack and the researcher decided that Ron should have a computer. This was not just because computers needed allocating (although this arguably played a part since only 12 users had been recruited and 13 more were needed - the researcher's research diary completed shortly after the visit identified how 'numbers needed filling in order to fulfil the remit of the initial proposal for the CommunITy project'). More substantively, he was accepted because he had simply been stuck in a bed for the past few years. He was accepted because the only real entertainment to which he had 24 hour access was his widescreen television. Jack and the researcher were made aware that Ron had difficulty sleeping, as he was in pain a lot of the time and that during the night he found it particularly difficult when he could not sleep. All he could do at these times was watch television (a computer, therefore, could give him something else to do at these difficult times). An additional factor was that Ron's sister had approached them in the hallway of his house and asked how long they thought he would have to wait for a computer, if accepted. She told them that her reasons for asking and seeming so "pushy" were that he had been promised many things from the organization in the 
past and that she would hate for him to have to suffer another disappointment. All of these issues were discussed by Jack and the researcher in the conversation that took place following the interview and were later reflected on and recorded in the researcher's diary. Jack formally completed the assessment form some days later and Ron was subsequently allocated a computer.

\section{Case Study 2: Chloe}

Some weeks later Jack and the researcher went to interview a 25 -year old woman (Chloe) who used a wheelchair and lived in a supported living scheme. When they arrived Chloe was with two carers and the researcher guided by the questions inscribed on the form began the interview. Questions such as 'what would you use the computer for?', 'would you use it for communication?' were put to Chloe who was struggling to respond. Shortly after the interview started, her mother entered the room and shouted "you're a week late, it was meant to be the $14^{\text {th }}$ and we're going out now" - the interview was subsequently re-arranged. Chloe's mother was present at the next interview. Jack and the researcher were quite anxious having the mother there, given her anger at the previous meeting so were happy to let the interview proceed as the mother pleased. It was learned that Chloe had had leukaemia when she was 7 years old and as a result of medical treatment, she had been left fully paralysed down the right hand side of her body, including one side of her brain. Chloe had difficulty communicating as a result of her impairments and her mother who was the main carer responded to the questions being asked that were inscribed on the form. Chloe was asked whether she would like to use the computer for online shopping. Her mother responded that she would not let her shop online as she liked to take her out as much as possible to do her shopping (they did not push for a more positive response, as they had with Ron). She added that Chloe also went out of the house a couple of days a week to visit day centres where she would meet up with many of her friends. 
After the interview, Jack and the researcher had a conversation in relation to her suitability for the project. They felt that because she gets out quite a lot, she did not fit the social isolation criteria of the project. However, they agreed that although she might not be socially isolated, she lacked independence largely because of the way her mother was highly protective of her. Thus the criteria of suitability were broadened to include independence since this enabled Chloe to be allocated a computer. So, as with Ron, the form set the scene but the embodied sociomaterial performances (which included the form) determined the outcomes.

Case Study 3: Polly

Another case involved Polly who was in her mid-sixties and had been diagnosed as having Lupus, Angina and Arthritis. Although able to walk, she tired very easily and got breathless with over-exertion and extremely uncomfortable if her body was positioned in a way that affected her impairments. Prior to the interview, the co-ordinator told the researcher that she "experiences depression from time to time as a result of being at risk of social isolation". At the interview, Polly had seemed like a dream in comparison to Ron and Chloe, in the sense that she responded positively to the questions about using a computer for purposes of social interaction. This allowed all the boxes to be ticked on the assessment form without having to manipulate the responses, or needing to persuade her that this was a potential solution to her social exclusion. Following, what could be termed, the successful nature of Polly's selection interview, she was allocated a computer.

Two months after the installation, Polly contacted Jack to inform him that she did not want the computer anymore. She told Jack she could not afford broadband and that she found the computer uncomfortable to sit at and to use. She told him how it was making her miserable, worrying about the discomfort and the cost and that really she had never wanted the computer in the first place. It can be seen here how the form served to constitute or sustain the welfare organization partly through Polly's concern to be socially accepted by responding positively to 
the interviewer's questions, thus allowing a computer to be allocated. Clearly in this case, however, while the organization was sustained through embodied sociomaterial relations, it was at the unanticipated expense of Polly's bodily and mental wellbeing. Polly's computer was returned and she was removed from the organization's database.

\section{Discussion}

As we have sought to argue, the problem for us is the paucity of discussion in the literature on the part that the form plays in the constitution of subjects, objects and organizational relations. In addition, when there are discussions of forms/documents more generally, the almost exclusive focus is on the texts and semantics rather than their implications for organizational relations. Our research has attempted to re-dress this imbalance by drawing attention to the embodied sociomaterial performances that take place as documents (in this case assessment forms) are enacted. In relation to these matters, the empirical data has demonstrated how at the beginning of Ron's interview it was becoming clear that he wanted to use the computer for 'buying and selling shares'. At the beginning of Chloe's interview, it was clear that her mother did not want her to shop online as she liked to take her out shopping, and at Polly's interview it seemed certain that she wanted the computer for interactional reasons which fitted well with the ideal of the project. In respect of all three cases and their potential suitability, one might say that the form (as designed by Jack) was shaping the limits and possibilities of the selection process (McLean and Hoskin, 1998). In order to become part of the CommunITy project and be allocated a computer, there was an assumption that candidates presumed a standardised subject position whereby they would want to use the computer for social interactional purposes. However, Ron and Chloe (or her mother) wanted the computer for different reasons and made that quite clear. From the very outset, then, Ron and Chloe's mother (unlike Polly) were not performing in accordance with expectations that were inscribed on the assessment form and this was becoming problematic. The form was designed, therefore, with the purpose of 
overcoming the marginalization of disabled people by increasing their sociability through digitalization. However, once enacted in these interview situations we see the instability of these expectations which became reconfigured in each and every empirical example discussed throughout this article.

Drawing on Smith (1978) we suggest that the performance and indeed outcome of all of these interviews is conditioned by the different interpretations of those involved in relation to the normative framework underpinning the project (i.e. to electronically compensate for the social exclusion of disabled people in society) and the form as an inscription device for determining and justifying outcomes. Yet these interpretations and the procedure of filling in the form became subordinate to achieving a material outcome of digitalizing disabled people through distributing computers to them.

In Ron's case, a range of interpretations of the different participants existed prior to the interview so that they were all 'singing from slightly different hymn sheets'. However as the questions on the form were addressed and became part of the performance, attempts were made to align the different interpretations, including those of Jack and the researcher, with the requirements of the project. In addition, the form symbolised the authority of Jack and the researcher as representatives of the non-profit organization and the presumed participation of a network of materialities, Ron and his carers. Following this line of thinking, these attempts were aimed at making everyone 'sing from the same hymn sheet' in order to constitute Ron as a suitable user. This was evident in relation to the question of why Ron wanted the computer for it was simply assumed that Ron would provide fitting answers that could allow the boxes to be ticked and enable him to become a CommunITy user. As is seen in the transcript, Ron's negative responses to questions about email, online shopping and social forums created difficulties in administering the form. 
Ron's interview transcript revealed he was resistant to answering the questions in a way that would allow the right boxes to be ticked. Chloe's mother also, seemed adamant not to be pushed (on Chloe's behalf) in the direction of, in her case, shopping online as she wanted to continue to take Chloe shopping during the week. Ron and Chloe (or her mother) were refusing to fit in with the rationale behind the project as inscribed in the form. None of these refusals to fit are documented on the completed assessment forms - they are indeed glossed over (Cooper, 1986). Polly was different in the sense that she responded (it seemed at the time) in a positive way to all the questions being asked. Usually particularly in public welfare, resources are limited and a competitive process takes place in order to distribute them to deserving cases. In such circumstances, we can assume that processes of allocation might run relatively smoothly. Here, however, because of the previous failure to allocate computers, resources were not scarce, yet the façade of a public display of competition and allocation on the basis of merit had to be maintained, as evident throughout the interviews. Polly was unaware of this failure and, we would suggest, saw this as a competitive process which led to her complying with requirements in an unproblematic manner in order to get a free computer. Perhaps had the process been informal and less focused on filling out the form, Polly may have intimated her reservations in advance of being allocated a computer and thereby not suffered the mental and financial anxieties it provoked. This discussion serves to demonstrate the power of the form in relation to the constitution of the CommunITy project and how it ascribes, confines, describes and enacts particular versions of bodies, people and practices. It highlights certain normative assumptions that are inscribed in the form; namely, of disabled people somehow lacking the ability to fully participate in the social world and therefore in need of a technological 'fix'. It also illustrates how these assumptions underpin the actions of Jack and the researcher when they seek to repair the performances. In addition, it alerts us to how these assumptions serve to marginalise disabled people as evidenced in the glossing over of Ron's wanting to buy stocks 
and shares, his frustrations that 'no-one was listening' to him, and Chloe's mother not wanting her to shop online.

We have evidence of the contribution of human agency/embodiment (Ron, Chloe, carers, co-ordinator etc.) and materialities (computers, beds, wheelchairs, forms etc.) and their different particularities in accomplishing and sustaining organizational practices through processes that are enacted before, during or after official selection interviews. For example, for Ron, the interview was about matching the IT to his impairment, for his carer the interview was about getting him something out of the organization which often in the past had not happened (albeit things had been promised), for Jack (the co-ordinator) the interview was about allocating resources and about helping disabled people increase their sociability and for the researcher the interview was about generating data to write a thesis and helping Ron to get a computer which she saw at the time (rightly or wrongly) as offering him a way of improvinghis life. Following the interview, Jack and the researcher discussed how even though Ron deviated from the expected responses that would have helped complete the form and identify him as a suitable user, he should have a computer anyway as this would likely increase his independence. The same was true of Chloe who was identified by Jack and the researcher as warranting a place on the project in order to increase her independence. This illustrates how the form and the form filling process was powerful in constituting not only the users but also the interviewers and occasionally marginalizing the agency of these disabled people by glossing over the sociomaterial, embodied relations.

However, like rules in a bureaucracy, the form was perhaps more about legitimizing rather than directly determining outcomes, for our research has shown how participants of the interview process negotiated their way around the inscriptions and prescriptions on the form. To illustrate, Jack and the researcher had their own interpretations of the project - conditioned arguably by the form, their own morality in dealing with disabled people, and their own 
pragmatic concerns - all of which led to the additional inclusion of independence eventually almost displacing sociability as a criterion of suitability, especially in the case of Ron and Chloe. The research provides evidence of the emergent, entangled and embodied 'ongoing materialising performance of the world (Barad, 2003 p.941)' which contributed to the 'repair work' that continually took place throughout these processes of selection. It reflects how the goals of the organization of distributing computers to reduce social exclusion as inscribed on the form were (re)interpreted to accommodate the discrepant behaviour of Ron and Chloe.

We illustrate these ongoing sociomaterial performances through some further empirical data since the researcher visited Ron again twelve months after the original research. Ron had bought a workstation with wheels and this enabled him to use the computer and voice recognition software but only when his carer or someone else was available to give assistance. They were needed to wheel the workstation into his small bedroom, to switch on the computer and to put on his headset, which he needed in place to use his voice recognition software. Ron also needed someone to be there when he had finished using the computer in order to take off his headset, turn off the computer and wheel the workstation out of the room. At that time, Ron was suffering from a great deal of neck strain which was a result of having to turn his head to the left hand side and look down slightly so that he could see his computer screen.

These continuing implications are also evident in the discussion of Polly and the events that took place two months following the installation of the technologies in her home. This is because Polly was suffering discomfort from sitting at the computer, and was worrying about the costs of broadband, and this eventually resulted in stress and the onset of depression. These were some of the events that led to Polly contacting Jack (the co-ordinator) and telling him she did not want the computer anymore and had never really wanted it in the first place.

In both examples we can identify notions of 'active embodiment' (Dale, 2005) where bodies cannot be seen as fixed entities independent of time and space. For bodies are continually 
changing as is the material world which they (we) inhabit, and different rationales are created and deployed to account for the diversity and the failure of the form to reflect this. The performance of Ron, Chloe (and her mother) and Polly in the selection process for the CommunITy project were conditioned in part by the assessment form/document, their bodies and the available technologies. They should therefore be identified as an ongoing and emergent embodied sociomaterial accomplishment in which multiple entities - in this instance the form - and the particularities of bodies (disabled/abled) and of materialities are involved in complex entanglements.

\section{Conclusion}

This article has presented an embodied sociomaterial analysis of how an assessment form facilitates and obstructs the selection/organization processes of fitting three users into the category of 'suitability' for the CommunITy project. We have demonstrated how documents such as the form and their social and organizational context generate limits and possibilities for applicants who seek to be 'suitable' users for the CommunITy project. However, these limits and possibilities are in turn conditioned as well as reproduced by the embodied, sociomaterial performances that surround the deployment of the assessment form. For example, Ron had suggested that his views were being ignored by the professionals who seemingly defined reality for him and, in this sense, we can see how the form was having the unintended effect of reinforcing a degree of marginalization. This was partly a consequence of how the CommunITy project embraced humanistic beliefs in disabled people realizing their potential through social communication, so that Ron's disinterest in the computer as a means of social interaction was a challenge to the charity's ethos and therefore had to be ignored. The computer was seen as a 'technological fix' in facilitating communications, regardless of whether it is the most appropriate way of doing so and of the extent to which this is even of any concern to particular disabled people. Such an imposition as a norm can have the effect of marginalizing disabled 
people even further, either by making them feel inadequate in not realizing themselves in this way or in feeling deviant by not complying.

It cannot be ignored how language and, in our case, the very concept of marginalization is 'performative' in the sense that it is active or consummates an action (Austin, 1970) and thus has an effect (Butler, 1990) in bringing about the very 'thing' to which it refers, or reproduces what it claims merely to describe (Latour, 2005). This occurs not merely because language and concepts are rarely innocent politically but also by virtue of simply marking disabled people out as in 'need' of special attention. This is one of the unintended consequences of welfare where there is a fine line between care and patronising power, which our case study illustrates quite sharply. It is partly why within the recent literature on ethics, traditional deontological, consequentialist and even virtue approaches have been criticised (Knights and O'Leary, 2006) in favour of a return to the ancient Greek focus on caring for others through first caring for the self (Foucault, 2011). For care is most effective when it is inscribed in everyday sociomaterial, ethical and embodied relations and not the end product of external interventions that have difficulty avoiding the charge of patronage, especially when they are informed by unreflexive humanist assumptions or are driven instrumentally to meet organizational targets and goals. Fortunately, Ron was a strong enough character not to be intimidated by this exercise of power implicit in the agency of the form, and to a lesser degree in the power of welfare agents. Also we should acknowledge that in everyday life this kind of ethical care is routinely practiced despite organizations and institutions imposing particular beliefs and procedures that can contradict it.

We have analysed the part that the assessment form plays in constituting and organizing the CommunITy project. In doing so, we have shown also how the assessment form is distinct insofar as it is incomplete until filled in whereas other documents relating to, for example, plans or strategy have an immediate effect upon action. Of course, the assessment 
form guides action, but does not actually determine it for, as we have seen in all three of the selection processes discussed, the organization of ongoing and emergent, embodied sociomaterial relations, as a form of 'heterogeneous engineering' (Law, 1987), facilitated an effective CommunITy project outcome.

Our stories of selection and how the assessment form is embedded yet transfigured or transgressed in the process allows us to display the bodies/materialities/documents and their intra-action with selection/organizing processes that were involved in the allocation of a computer to disabled people in this empirical setting. In addition, our empirical research and analysis on the deployment of assessment forms in allocating computers to disabled people draws explicit attention to the enactments of agents, technologies and their representations in interviews concerning the sociomaterial and embodied relations and the social organization of charitable work. What we have demonstrated is that the form to be written and the written form always continues to 'matter' throughout processes of selection, but that to explore 'how' it continues to 'matter', there is a need to understand the enactment of forms as a complex embodied, sociomaterial performance whose outcome cannot be wholly predicted.

In summary, our contribution has been to address the paucity of discussions of forms in organization studies, which results in a neglect of the part they play in the constitution of subjects and organizations generally, and specifically in our example of the charitable distribution of technology to disabled people. In particular, it has sought to compensate for the limited research of embodied sociomaterial performances that ensue as forms or documents are enacted within situated and practical circumstances. Theorizing these enactments has enabled us to identify how forms and form filling processes shape our organizational realities and how an overfocus on forms can lead to a glossing over/obscuring of the ongoing performances that are taking place in situated practice. We have identified how these performances are themselves 
entangled with forms and form filling and shown how organizational and indeed social reality is a complex outcome of engagement with these entanglements.

An important implication of this research, which has become increasingly evident throughout the review process, is how disabled people can readily become marginalised. This occurs not just through conventional processes of stigmatization but also because of normalising procedures that define disabled people as lacking something, such as 'good' social and communicative relations, and in our research, seeking to deploy technology as a way of restoring it regardless of whether or not this is their priority. A significant conclusion of our research is to argue that insofar as humanistic assumptions about sociability as well as realising human potential are prevalent within charitable organizations, they may have the unintended effect of normalising, rather than embracing difference, thus contributing to, rather than eliminating, the marginalization of the recipients of welfare. While this is of practical concern for the disabled people in our study, it may have much wider implications for welfare in general.

\section{REFERENCES}

Atkinson P and Hammersley M (1994) Ethnography and Participant Observation in Denzin N L \& Lincoln Y. YS (eds). Handbook of Qualitative Research, (pg.248-261), Sage.

Austin JL (1970) "Performative Utterances." In Austin, "Philosophical Papers", 233-52.

London: Oxford University Press.

Barad K (2003) Posthumanist performativity: Toward an understanding of how matter comes to matter, Signs, 28(3), 801-831.

Barad K (2007) Meeting the Universe Halfway: quantum physics and the entanglement of matter and meaning, Duke University Press.

Barad K (2011) Nature's Queer Performativity, Critical Humanities and Social Sciences, 19, 2, 121-158. 
Barad K (2013) Ma(r)king Time: Material Entanglements and Re-memberings: Cutting Together-Apart (Chapter 2:16-31) in Carlile P R, Nicolini D, Langley A and Tsoukas H (eds) How Matter Matters (2013), Oxford University Press.

Bittner E (1967) The police on skid row: A study of peace keeping, American Sociological Review, 32(5): 699-715.

Bloomfield BP, Latham YL and Vurdubakis T (2010) Bodies, Technologies and Action Possibilities - When is an Affordance, Sociology, 44(3): 415-433.

Braidotti R (2011) Nomadic Theory: the Portable Rosi Braidotti, Columbia University Press, Kindle Edition.

Butler J (1990). Gender Trouble. New York: Routledge.

Coffey A (1999) The Ethnographic Self, SAGE.

Cooper R (1986) Organization/Disorganization, Social Science Information, 25(2): 299-335.

Cooper R (1993) ‘Technologies of Representation' in P. Ahonen (ed.) Tracing the Semiotic Boundaries of Politics. Berlin: de Gruyter.

Cooper R (2001) ‘Interpreting Mass: Collection/Dispersion’ in N Lee and R Munro (eds), The Consumption of Mass, Oxford, Blackwell: 16-43.

Cooren F (2004) Textual Agency: How Texts Do Things in Organizational Settings, Organization, 11, 3, 373-393.

Cooren F, Kuhn T, Cornelissen JP, Clark T (2011) Communication, Organizing and Organization: An Overview and Introduction to the Special Issue, Organization Studies, 32(9), 1149-1170.

Dale K (2005) Building a Social Materiality: Spatial and Embodied Politics in Organizational Control, Organization, 12(5): 649-678.

Dale K and Latham Y (2015). Ethics and entangled embodiment: Bodies-materialitiesorganization. Organization, 22(2), 166-182. 
Foucault M (2011) The Courage of Truth: Lectures at the College de France 1983-4,

Basingstoke: Palgrave Macmillan.

Garfinkel H (1967) Studies in Ethnomethodology, Prentice Hall.

Grosz E (1994) Volatile Bodies: Toward a Corporeal Feminism, Bloomington IN: Indiana University Press.

Harding NH, Ford J, Lee H (2017) Towards a Performative Theory of Resistance: Senior Managers and Revolting Subject(ivitie)s, Organization Studies, 38(9), 1209-1231.

Holmqvist M, Maravelias C and Skalen P (2012) Identity regulation in neo-liberal societies: Constructing the 'occupationally disabled' individual, Organization, 20(2), 193-211.

Iedema R (2007) On the Multi-modality, Materiality and Contingency of Organization Discourse, Organization Studies 28(6): 931-946.

Knights D and O'Leary M (2006) Leadership, Ethics and Responsibility to the Other, Journal of Business Ethics, 67, 2: 125-137.

Latour B (2005) Reassembling the Social. Oxford: Oxford University Press.

Law J (1987) 'Technology and Heterogeneous Engineering: the Case of the Portuguese

Expansion', in Wiebe Bijker, Thomas Hughes and Trevor Pinch (eds.), The Social

Construction of Technological Systems, Cambridge, Mass., M.I.T. Press: 111-134.

Law J (2008) On sociology and STS, The Sociological Review, 56(4).

Lennie I (2001) Language that organizes: plans and lists (Chapter 3:47-66), in The Language of Organization, Westwood R and Linstead S (eds), SAGE.

McLean C and Hoskin K (1998) Organizing Madness: Reflections on the Forms of the Form, Organization, 5(4): 519-541.

Mol A (2002) The Body Multiple, Duke University Press, Kindle Books.

Mol A and Law J (2004) Embodied Action, Enacted Bodies: The Example of Hypoglycaemia, Body \& Society, 10(2-3): 43-62. 
Moser I (2005) 'On Becoming Disabled and Articulating Alternatives: The multiple modes of ordering disability and their inferences', Cultural Studies (6): 667-700.

Moser I and Law J (2003) Making voices": New media technologies, disabilities, and articulation. Digital media revisited: Theoretical and conceptual innovation in digital domains, 491-520.

Orlikowski WJ (2007) Sociomaterial Practices: Exploring Technology at Work, Organization Studies 28(09): 1435-1448.

Price J and Shildrick M (2002) Bodies Together: Touch, Ethics and Disability (Chapter 5:6275) in Disability/Postmodernity, Embodying disability theory (eds) Corker M and Shakespeare T.

Pullen A, Rhodes C and Ten Bos R (2015) Special Issue on Ethics, Embodiment and Organization, Organization, 22/2.

Reed A (2006) Documents Unfolding (Chapter 5:158-177) in Documents: Artifacts of Modern Knowledge, Riles A (2009) (ed), The University of Michigan Press.

Rhodes C and Brown A (2005) Writing Responsibly: Narrative Fiction and organization Studies, Organization, 12(4): 467-481.

Shildrick M and Price J (1996) Breaking the Boundaries of the Broken Body, Body and Society, 2(4): 93-113.

Shildrick M (2009) Dangerous Discourses of Disability, Subjectivity and Sexuality, Palgrave MacMillan.

Smith D E (1978) ' $\mathrm{K}$ is mentally ill' - The Anatomy of a Factual Account', Sociology,12(1): 23-53.

Spinoza B (1955) On the Improvement of Human Understanding: The Ethics and Selected Letters, trans. R.H.M. Elwes, New York: Dover.

Thanem T and Knights D (2019) Embodied Research Methods, London: Sage. 
Wacquant L (2006) Body and Soul, Oxford: Oxford University Press.

Wacquant L (2015) For a Sociology of Flesh and Blood, Qualitative Sociology, 38:1 11.

Williams J and Mavin S (2012) Disability as Constructed Difference: A Literature Review and

Research Agenda for Management and Organization Studies, International Journal of

Management Reviews, 14, 159-179.

\footnotetext{
${ }^{\mathrm{i}}$ All names of participants and organization are pseudonyms.

ii We use the term document and form interchangeably in the article although the former term takes precedence in the title. The limited literature tends to use the term form.

iii Mol (2002) suggests 'that in the act, and only then and there, something is-being enacted' (p. 32).

iv The researcher was also involved with the installation of all 25 computers and visited the 25 selected users to evaluate their use of the computers some 3 to 4 years after the allocation. She also kept in contact with a number of users for several years, one of whom she last visited and re-interviewed in 2016.

v This is evident in the transcript taken from Ron's interview.

${ }^{v i}$ Other sections omitted questions such as name, address, registered doctor, convenient times for volunteer to visit, etc.

vii A possum is an environmental control system, which in this case was operated by blowing into a tube which is fixed in a position close to Ron's mouth in order to make it easily accessible to him.

viii Although buying stocks and shares involves some social interaction this is rather minimal unless employing a stockbroker

ix These aims were inscribed on the proposal document that had been discussed at length, and as a result underpinned much of their thinking.
} 